\title{
Colonization of space: destiny or folly?
}

\author{
Von R. Eshleman
}

\section{The US National Commission on Space has grandiose plans for the colonization of the Solar System. Has the view that unmanned missions may bring much greater benefit to mankind been passed over?}

THE presidentially-appointed National Commission on Space has recently released an expansive agenda for the US space programme in the first quarter of the twenty-first century (Pioneering the Space Frontier, Bantam Books, Inc., New York, 1986). With space enterprise, exploration and science as components, the overall rationale behind this vision of the future is founded on an assumption: that the human species is destined, within the foreseeable future, to colonize space.

But this assumption is not critically examined. It is offered as an act of faith, as though it were rendered self-evident by references to Columbus and 'The New World', the settlement of the American West, and the pioneering spirit that has served us so well in the past.

These are indeed powerful images, but do they necessarily make space colonization a human imperative? I do not question whether it could be done so much as to wonder why it is assumed that it should be done. I would worry about unresolved difficulties, but my main concern is the danger of precluding alternative possibilities of greater promise.

The commission envisages that by the year 2000, the United States would have an Earth Spaceport, with crew, for storage, fueling, repair, supply, maintenance, and launch of transfer and orbital manoeuvering vehicles for access to more distant locales. By the year 2025 there would be: three additional spaceports with human crews, including one near Mars; staffed spaceships continually cycling between the orbits of Mars and Earth; manufacturing at a permanent human base on the Moon; astronaut outposts on Phobos and Deimos, the small moons of Mars; and an exploratory base on the surface of Mars which would become a fully-staffed permanent base within a few years. It is stated that this 'Highway to Space' and 'Bridge Between Worlds' would provide the infrastructure for space applications and science, while serving as a focal point for international cooperation and advances in technology. And it would initiate the colonization of the Solar System.

Will this proposal for pioneering the space frontier prove to be prophetic or visionary? It is intended to help influence future events so as to become the former, but current events and their origins suggest that it could well be the latter. It is my opinion that the commission's proposals, if initiated, would lead to a continuation of the fundamental failure of the US space programme to use national resources most effectively for progress at the frontier of space. The crux of the problem, I submit, is an inappropriate mix of the relative influences of our space ends and means. and sometimes dreams.

In the report, for example, it is the dream of colonization that determines the proposed infrastructure of spaceports, cycling spaceships and lunar and martian bases. But these are simply means; the ends are primarily the exploration and commercial and scientific use of the space environment. Is there not a danger that the means will become ends in themselves? The question is not even asked the other way around. If all manner of space manufacturing, Earth remote sensing, space communications, planetary exploration, and space science laboratories and observatories are indeed our main ends, by what means may they best be realized? This inevitably brings up the decades-old debate concerning the relative importance and roles of manned and unmanned space endeavours. In the commission's view, the debate is finished. Human crews, settlers, and vacationers belong wherever they conceivably can go. In this scenario, the next frontier will be conquered as before, with a wave of human pioneers.

\section{Ultimate frontier}

But mankind could expand into the ultimate frontier of space in another way. Never before have we had the ability to observe, explore, utilize, examine, monitor, manipulate, prospect, mine and manufacture, or in short pioneer and operate at a new physical frontier, without the necessity of a physical human presence at that frontier. In a way, humanity as a whole could experience its continuous expansion into thousands of locales at the frontier of space, with a multitiude of its doers (like the hand of Viking 1 as it clutched a sample from an ancient plain of Mars) and sensors (like the eyes of Jason $\mathrm{Jr}$ as it descended the grand staircase of the Titanic or the magnetometers of Voyager 2 as they charted the bizarre field of Uranus) on the ends of thousands to billions of kilometre-long radio nerve fibres and commandable sinews. Remote human monitoring and control of space manufacturing and delicate experimentation could also be accomplished.

The means to secure these ends would be low-cost unmanned launch and transfer vehicles and new levels of capabilities in robotics, communications and control, adaptive and expert systems, and many related technologies. Our collective space dreams could encompass the endless possibilities for international cooperation in obtaining new knowledge, products and resources from space in this way, and the endless potential of applying them to better the human condition on Earth. Such dreams include an automation revolution to rival the industrial revolution in significance, and new levels of understanding of climatic effects like carbon-dioxide warming, nuclear winter and acid rain from remotely controlled examinations of related phenomena on other worlds. Concerns about national prestige and demonstrations of technological prowess, as with Apollo, or dreams about solving international tensions by a joint symbolic venture in space, such as a human mission to Mars, do not appear to me to be useful guides for progress.

The current hiatus in American access to space due to the Challenger disaster should be used to re-appraise our goals and the methods for their realization. It is clear that the present problems would have surfaced in some way, even if the tragic accident had not occurred. Although many observers have cheered the decision by President Reagan to replace Challenger, some seem to have missed the significance of the accompanying announcements that the United States will phase out commercial and foreign payloads for the shuttle fleet, and will encourage the commercialization of launch services after the 15-year delay that was enforced by nationally-subsidized competition. This stands as a tacit admission that we have failed to realize the fundamental rationale for the space shuttle programme, namely, that of providing low-cost access to space for all US and many foreign users.

The shuttle experience stands as one example of the kinds of things that could go wrong if we try to bypass incremental, well-funded, long-term progress based on carefully defined goals and feasible, costeffective means tailored to those ends. I submit that space colonization is a dream whose time has not yet come, and that the benefits of the space frontier beckon us to realize them in the most direct and effective ways possible.

Von R. Eshleman is Director of the Center for Radar Astronomy, DB221, Stanford University, Stanford, California 94305, USA. 